\title{
TEACHING PRACTICES OF COMPUTER-AIDED TECHNICAL DRAWING IN THE TIME OF COVID-19
}

\author{
Maurício BERNARDES and Geísa OLIVEIRA \\ Federal University of Rio Grande do Sul
}

\begin{abstract}
This paper aims to describe the teaching practices of computer-assisted technical drawing used during the Covid-19 pandemic. Such practices intend to encourage the engagement of students with the implemented approach. The research was carried out by analysing the data from five technical drawing Engineering and Design courses in a Brazilian public university. Data were collected between August and October 2020 based on the observations by the authors of this paper and on an online questionnaire submitted to the students of the referred courses. The data were analysed at four different moments: selection of teaching technologies in virtual learning environments, planning, implementation, and course assessment.

The study findings revealed higher student engagement when unconventional practices, such as gamification, were used in the classroom, as well as the use of reference animation pieces to serve as the basis for the drawing, and a small number of assignments to be performed with mandatory appraisal from the professors. Another finding indicated that the quality of remote instruction and guidance is conditioned by the evolution of the technological apparatus and its availability at the university with the support and exposition of contents and real-time feedback.
\end{abstract}

Keywords: Technical drawing, CAD, remote classes, Covid-19

\section{INTRODUCTION}

Computer-aided technical drawing is a basic academic discipline in Engineering and Design undergraduate courses, which focuses mainly on presenting local and international standards. It also aims at incorporating technological innovations in the area of computer-assisted design. The professor must follow the student's progress and provide real-time feedback during in-class assignments. Due to the pandemic, the pedagogical approach used in these courses had to be revised and updated. This paper describes practices used in technical drawing disciplines with the support of CAD systems at a public university in Brazil during the period of the Covid-19 pandemic. The authors chose to use teaching strategies that favoured the teaching and learning process based on remote approaches, as proposed by [1].

The practices resulted from discussions among the discipline professors regarding more appropriate teaching formats, contents, and student evaluation processes. Also, the theoretical reference in the area was used to support or refute our propositions. Data contained in the observations made by the professors who authored this paper were also used to implement the remote format of the discipline, as well as an analysis of the students' opinion, obtained through an anonymous online questionnaire at the end of the academic semester.

\section{CONTEXTS FOR THE STUDY}

The technical drawing discipline with CAD system support is mandatory for most of the Engineering and Design undergraduate courses offered by the university in question. Every semester, it offers 12 technical drawing classes with CAD system support. There are two types of classes: specific and generic ones. The specific classes are offered for the Civil Engineering, Mechanical Engineering, Production Engineering, and Agricultural Sciences courses. The generic ones are offered for Design, Food Engineering, Chemical Engineering, Mining Engineering, Cartographic Engineering, Electrical Engineering, Automation and Control Engineering, Environmental Engineering, and Hydraulic Engineering courses. All disciplines present the same theoretical content for technical drawing. However, there are additional modules aimed solely at their respective areas of knowledge for the 
specific disciplines. For example, the discipline offered in Civil Engineering courses includes a building design module.

At the university, the classes are assigned to a team of eight professors. Each specific class, in general, has a total class load of 90 hours per semester and 60 hours for the generic classes. On average, 360 students are enrolled every semester. When a class has, in general, more than 25 students enrolled, two professors are assigned to teach in the classroom since it is necessary to provide individualized assistance for each student. Our experience shows that in classes with more than 25 students, it is not possible to provide adequate individual assistance with only one professor in the classroom during the class period. The discipline also has 4 monitors that take turns providing support for all the classes. Historically, there is no possibility of increasing the number of monitors due to budget restrictions of the university. Despite the budgetary difficulties, the university is among the best ranked by the Brazilian Ministry of Education.

Unlike American and European universities, in Brazil, the school year is divided into two semesters, with classes from March to July and August to December. The university in question has 29 thousand undergraduate students and had its classes and activities suspended in the third week of March 2020. The classes resumed in a remote format in August. The four months of the first semester were used to create a statute to legally regulate the remote teaching format, conferring it with the same status of inperson classes at the university. For the remote teaching mode, we adopted the definition of [2], which refers to the context of teaching the classes with asynchronous and synchronous content, without on-site meetings.

Before the pandemic, concerning the technical drawing disciplines supported by CAD systems, seven of the eight professors opposed the possibility of offering classes in hybrid or remote modalities. According to these professors, face-to-face contact is fundamental since it allows them to better monitor the students' evolution and because the tests can be applied with a low risk of cheating. Also, research evidence shows that the students' satisfaction with the course is lower in online classes than in face-toface classes [3].

The four months following the suspension of classes were marked by uncertainty. However, the discipline professors used that time to study means to adapt it to remote teaching. Most of the information technologies considered were free of charge to facilitate student access. It is important to point out that the discipline already used the Moodle platform to provide information for face-to-face classes.

With the information that the University had acquired a Microsoft Teams educational package to enable synchronous remote classes, the professors began the respective adaptation. The disciplines were initially structed with the intention, above all, to engage students in remote classes since it is known that changes in their routine can cause students to abandon class attendance [4].

To conduct this research, data collected from five technical drawing courses in Engineering and Design were used. Data were collected between August and October 2020 based on the observations by the authors of this paper and on an online questionnaire submitted to the students of the referred courses. The observations concern the students' questions during the classes and the evaluations of the asynchronously applied tests. Only the classes assigned to the authors of this paper were analysed, comprising 72 students in total. The return rate was $55 \%$. The data were analysed at four different moments: selection of teaching technologies in virtual learning environments, planning, implementation, and course assessment.

\section{TEACHING PRACTICES ADOPTED}

\subsection{Selection of teaching technologies in virtual learning environments}

The search for technologies made available by the university as virtual learning environments constitutes the first stage of a strategy aimed at implementing remote teaching approaches [5]. Resources should also be implemented to make the class attractive and preferably available free of charge on the Internet [6].

The University studied here uses Moodle and MCONF. However, with the increased use demand due to the pandemic, MCONF proved unstable. That led them to acquire the Microsoft Teams educational package. The technical design professors compared MCONF and Teams based on the available resources in each environment and their stability and opted for Teams. Once the platforms used were chosen, they could move on to the pedagogical planning of the discipline. 


\subsection{Planning}

The professors are responsible for planning the course in the remote format [5]. Among their objectives, they must seek to increase student engagement and decrease the chances of evasion. In this sense, some practices adopted during planning are essential to achieve the objectives established by the professors:

- Relate the discipline to professional practice: during the classes, we tried to exemplify the practical application of the theoretical contents, according to what was established in [7].

- Prepare tests according to the complexity of the exercises performed in class: tests must have the same complexity as in-class or out-class assignments. However, note that the same rule applies to remote classes. They must be planned to increase the complexity of the proposed exercises to train students for more complex problems.

- Avoid having a large number of assignments during the course: a smaller number of assignments provides a sense of completeness and increases the students' satisfaction as they achieve the course goals [8]. This was a point of dissatisfaction for some students in three studied groups with assignments to be completed in all classes.

- Make video lessons of the subject contents available before the day of the class: in this sense, professors can adopt the flipped classroom approach [9] to make use of the synchronous class period for professor-student feedback, making the class more discursive and attractive.

- Develop dynamics to make the classes more attractive and increase engagement: A dynamic exercise was developed through Quizzes in one of the classes. According to [10], there is a positive relationship in the students' motivation through such activities.

- Such activities are extremely important to increase student engagement and integration. They were particularly used to break the ice between the teacher and the students, which was sometimes noticed in remote classes at the beginning of the semester. It is recommended that they be used at the end of the first $1 / 3$ of the course as a way to increase engagement and help students consolidate the contents. In the courses, there was room for a single activity of this type. Dynamics of this nature require a greater number of classes, since the content of the teaching plan to be worked on must be prioritized.

- Develop, along with two-dimensional images, three-dimensional animations of the pieces to be drawn by the students: the use of animations to facilitate the understanding of the format of elements or provide a visualization experience close to reality has a positive effect on the learning process of the students [11], since physical pieces, traditionally used in the discipline, were not available due to the need to maintain social isolation.

\subsection{Implementation}

The process of implementing the pedagogical plan of the discipline allowed us to identify the need to work with specific operational practices:

- Introducing the operational plan of the discipline in the first class in more detail than in face-toface classes: this plan needs to detail all the content that will be worked on and when and how the students will be evaluated. Thus, the students get a better view of the path that will be followed since the beginning of the course. Preferably, the links for the recorded video lessons should already be available in the plan, associated with each lesson.

- Organizing and presenting the classes in a logical sequence regarding the content to be delivered. The qualification to use the CAD system should be the course's starting point. Then, contents that improve the student's capacity for spatial visualization should be developed. Finally, we work with drawings intended for the application of standards and project development.

- Making available extra-class hours for students: besides helping students who have had their routines disrupted by the pandemic, these hours allow greater student engagement, increasing their satisfaction [3].

- Quickly answering students' questions: by giving a prompt response to questions, the timing of the student's learning process is not disrupted. We chose to create rooms for solving individual doubts within the virtual learning environment to facilitate the process of exposing the problem, mainly to assist cases of introverted students.

- Providing a greater number of exercises with answers: it was noticed that there are students who ask for exercises and their respective answers to practice outside the class. This contributes to their learning process. In the remote format, there was a greater demand for these types of exercises by 
students.

- Recording all synchronous classes: in times of pandemic, it is important to know that there will be students who will not be able to attend synchronous classes due to routine issues. Making the recordings available helps students to review the contents and make their study schedules more flexible.

- Using technological resources that allow remote access to the student's computer: these resources are essential to enable a humanized professor-student service and approach (Figure 1). However, their use should consider the Internet connection service of the professor and the student and their computers.

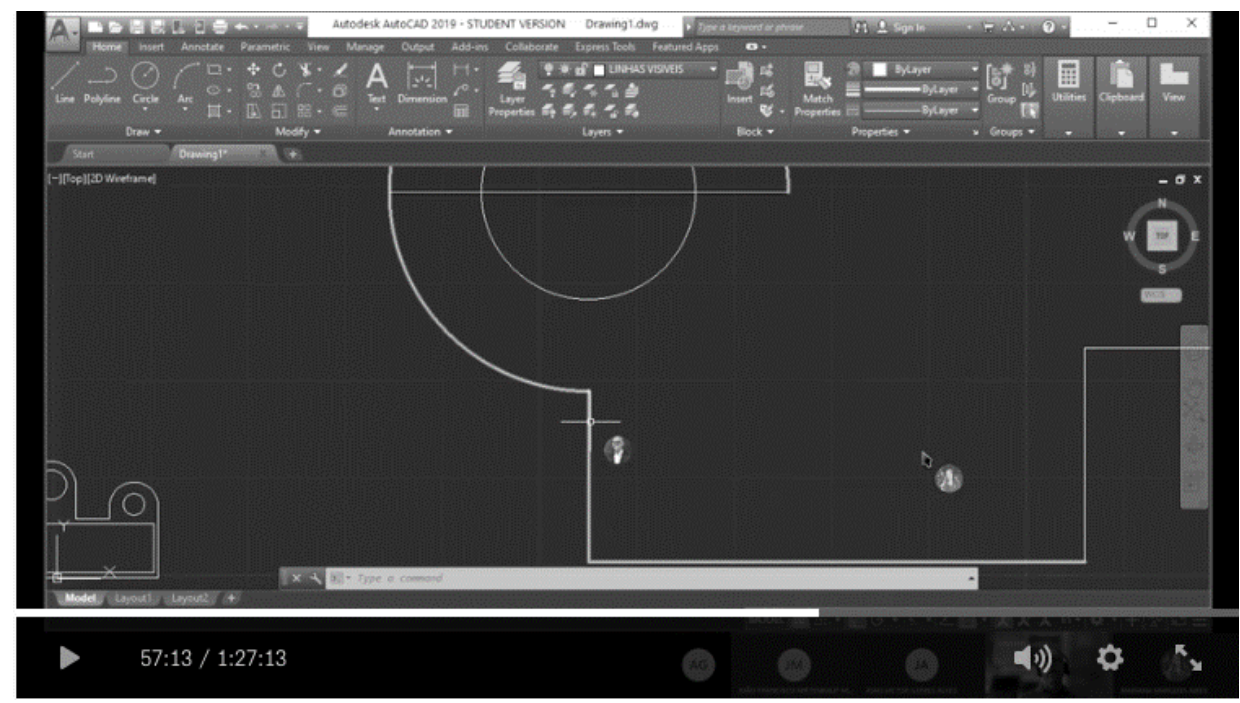

Figure 1. Remote access to a student's computer

\subsection{Course Assessment}

The first academic semester of 2020 officially ended on December 2, 2020. In the last two weeks of the semester, the authors of this paper invited their students to answer an anonymous questionnaire regarding the teaching practices employed. The students' preference by class type at the end of the semester during which the pandemic occurred was distributed as follows: $60 \%$ prefer remote classes, $32 \%$ hybrid classes, and $8 \%$ in-person classes. Some students have pointed out that the way in which the course is conducted enables it to be carried out completely remotely. One of the students said the following: "I really liked the discipline, it was very didactic, and I don't see the need for this class to be completely face-to-face, the tests must be in person, but the content of the discipline can totally be presented online." Regarding the difficulty of participating in synchronous classes, $60 \%$ of the students stated they had trouble attending some classes. From those, $45 \%$ informed that they preferred to watch the recorded class videos at other times; $32 \%$ had other activities in their routine to perform; $18 \%$ emphasized that the videos were enough to provide understanding and that there was no need to attend the synchronous classes; and 5\% of the students started internship during the times of the classes.

Although $22 \%$ of the students did not have difficulty with the classes, $43 \%$ of the respondents listed their study and work routines as the main difficulties (Figure 2). During the synchronous class period, the students' main difficulties were related to their study and work routines. [12] states that one way to deal with routine issues is to provide the most appropriate class format in a flexible manner, according to the student's specific times. Thus, students can transition from a completely online model to a hybrid model at their convenience. 


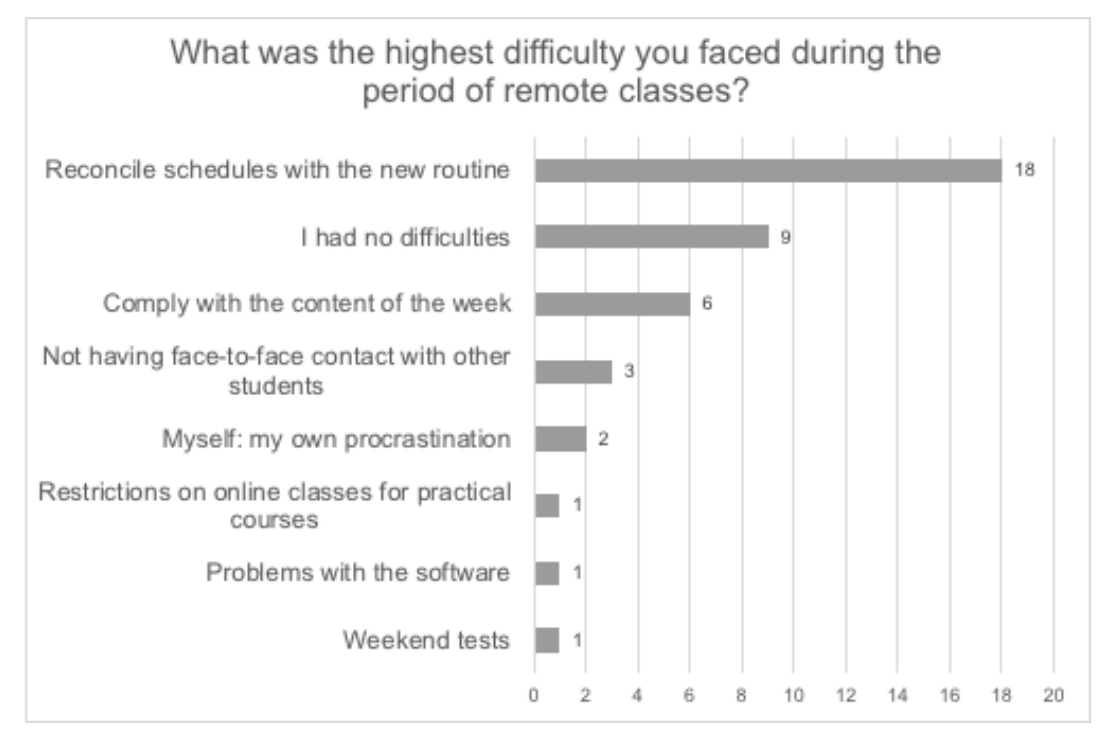

Figure 2. Main difficulties faced by students in remote classes

The students' evaluation showed that most of the practices adopted were successful. On a scale of 1 to 4, with 1 being "I totally agree" and 4, "I totally disagree," Table 1 presents an average of the students' responses. However, the partial disagreement with the high number of weekly assignments (analysis topic number 6) should be noted. The answer may be justified by the students' difficulty in managing their study time and due to changes in their routine - the main difficulties found by the studied group.

Table 1. Evaluation of practices adopted by students

\begin{tabular}{|c|c|}
\hline Analysis Topic & $\begin{array}{c}\text { Average } \\
\text { Mark }\end{array}$ \\
\hline 1. Classes were organized and presented a logical sequence. & 1.10 \\
\hline 2. I knew in advance what would be covered in each class. & 1.40 \\
\hline $\begin{array}{c}\text { 3. The course schedule was detailed with the theoretical subject and practical exercises } \\
\text { and it was accomplished. }\end{array}$ & 1.13 \\
\hline 4. The videos of the classes were made available in advance. & 1.18 \\
\hline 5. I missed exercises to practice. & 3.63 \\
\hline 6. There was a large volume of assignments. & 3.00 \\
\hline 7. The tests were compatible with the subjects covered. & 1.28 \\
\hline 9. The professor used innovative resources to hold students' attention. & 1.20 \\
\hline 9. The professor, when asked, solved the students' doubts. & 1.08 \\
\hline 10. The professor was accessible to students during class hours and outside class hours. & 1.15 \\
\hline 11. The professor related the discipline of DTII with professional practice. & 1.53 \\
\hline
\end{tabular}

\section{CLOSING REMARKS}

The practices adopted in the discipline were followed in full. The analysis of the applied questionnaire allowed us to identify that its implementation was successful. In addition to the practices adopted, it should be noted that professors tried to deal with the adaptation of remote teaching with effort and enthusiasm, corroborating what was stated in [3]. One cannot face something new without research and preparation for the new context. The four-month period for understanding the problem, learning new technological resources, and studying the new legislation in force were essential for successfully adapting the technical design discipline to the remote format. Other initiatives have proved promising. In one of the studied classes, the "Who Wants to Be a Millionaire in Technical Drawing?" dynamic was used, with questions and answers, suspense music, and an award called "Prestige." Whoever got the answer right won a Prestige award, which gave the student power to increase his/her mark on the subject at the end of the semester. Another important point was the availability of 3D pieces to support the exercises according to the students' feedback. The course assessment showed a strong engagement of 
the students and the professor in the activity, corroborating what was explained in [13]. The professors, however, had their workload increased to offer extra-class assistance to the students.

The experience allowed students and professors to demystify the use of new technologies that make the teaching-learning process more attractive, in line with the research by [14]. The process adapting and implementing remote teaching for technical design has changed the idea that it is not possible to deal with a subject of this nature online. The group of professors of the discipline elaborated a plan to offer it both in person and in hybrid format with in-person tests after the pandemic.

\section{REFERENCES}

[1] Aperribai L., Cortabarria L., Aguirre T., Verche E., and Borges Á. van Wezel W. Teacher's Physical Activity and Mental Health During Lockdown Due to the Covid-2019 Pandemic. Frontiers in Psychology, 2020, 11, doi: 10.3389/fpsyg.2020.577886.

[2] Hodges C., Moore S., Lockee B., Trust T., and Bond A. The Difference Between Emergency Remote Teaching and Online Learning. EDUCAUSE. Available:

https://er.educause.edu/articles/2020/3/ the-difference-between-emergency-remote-teaching-andonline-learning/ [Accessed on 2021, 3 February], (2020) 27 March.

[3] Summers J. J., Waigandt A. ad Whittaker T. A Comparison of Student Achievement and Satisfaction in an Online Versus a Traditional Face-to-Face Statistics Class. Innovative Higher Education, 2005, 29(3), 233-250.

[4] Rovai A. Building Sense of Community at a Distance. International Review of Research in Open and Distance Learning, 2002, 3(1), 1-16.

[5] Swanson D. and Casner M. Hybrid, It is More Than Fuel Efficient. In Proceedings of the 2009 ASCUE Summer Conference, North Myrtle Beach, South Carolina, June 2009, pp.153-161 (Peter Smith, Saint Mary's College, Notre Dame, IN).

[6] Singh A., Mangalaraj G., and Taneja A. Bolstering Teaching through Online Tools. Journal of Information Systems Education, 2010, 21(3), 299-311.

[7] Saccente F. The real world meets the technical drawing curriculum. Technological Horizons In Education, 1994, 21(8), 72-73.

[8] Grady J. Improving Student Satisfaction with Large-Scale, Compressed Timeline Online Courses. The Quarterly Review of Distance Education, 2013, 14(4), 195-208.

[9] Awidi I. and Paynter M. The impact of a flipped classroom approach on student learning experience. Computers \& Education, 2019, 128, 269-283.

[10] Raes A., Vanneste P., Pieters M., Windey I., Noortgate W. and Depaepe F. Learning and instruction in the hybrid virtual classroom: An investigation of students' engagement and the effect of quizzes. Computers \& Education, 2020, 143, https://doi.org/10.1016/j.compedu.2019.103682.

[11] Yigal R. The Effects of an Animation-Based On-Line Learning Environment on Transfer of Knowledge and on Motivation for Science and Technology Learning. Journal of educational computing research, 2009, 40(4), 451-467.

[12] Lightner C. and Lightner-Laws C. A blended model: simultaneously teaching a quantitative course traditionally, online, and remotely. Interactive Learning Environments, 2016, 24(1), 224238.

[13] McIntosh J. Using games to drive engagement in the classroom. Welding Journal, 2015, 94(4), 48-50.

[14] Bennett G. and Green F. Student Learning in the Online Environment: No Significant Difference? Quest, 2001, 53(1), 1-13. 